\title{
LA VAGUEDAD COMO PROBLEMA LINGÜISTICO EN EL CAMPO JURÍDICO
}

Enrique Vigil Oliveros ${ }^{1}$

\section{SUMARIO}

1. Introducción. 2. Planteamiento del problema. 3. Problemas de contexto lingüístico. 4. Aplicación de la vaguedad en el sistema jurídico. 5. La necesaria existencia de la vaguedad en la legislación. 6. La vaguedad en las resoluciones judiciales. 7. Conclusiones.

\section{RESUMEN}

El presente artículo tiene como idea principal analizar la repercusión de la vaguedad como problema lingüístico en la motivación de las resoluciones judiciales. Los jueces para evitar este problema utilizan otros términos; sin embargo, es indudable que en una resolución puedan encontrarse estas deficiencias por desconocimiento del magistrado o en muchos casos porque la vaguedad también puede estar inmersa dentro de la propia Ley. Por ello, es posible que la argumentación jurídica subsista irremediablemente con la vaguedad no solo a nivel de la fundamentación jurídica sino también a través de la norma cuando ella ha sido creada entre otros factores sin un análisis lógico y semántico. En este artículo el análisis buscará la solución a través de superar la vaguedad construyendo el contexto lingüístico.

\section{PALABRAS CLAVE}

Vaguedad, semántica, interpretación, palabras vagas, léxico, ambigüedad, comunicación, imprecisión, contexto, lingüístico, significado jurídico, pretensión, razonamiento, decisiones judiciales.

\section{INTRODUCCIÓN}

El lenguaje es un campo sumamente complejo diversificado por varias palabras, significados, entre otros, sujetas a la interpretación de cada persona para entender una determinada comunicación, oración o frase; sin embargo, en algunas ocasiones el lenguaje resulta ser un arma de doble filo para los que viven en el mundo del derecho, ya que su interpretación tendrá una su- jeción en la normativa, en la pretensión de una demanda, o en general en un dialogo con nuestros clientes o tal vez en el dialogo que tengamos con un juez, o algún tema que se subsuman un contexto legal.

En algunas ocasiones el ámbito jurídico, a diferencia del lenguaje común de las personas, puede ser un poco reservado para adaptar una posición legal adecuada, ya que para sustentar ciertas pretensiones que queremos solicitar debemos de recurrir al instrumento normativo; sin embargo, lamentablemente en algunas ocasiones la normativa puede demostrar vacíos o lagunas legales susceptibles a tergiversar el lenguaje, con la finalidad de acoplar un caso práctico a la defensa de un caso, con lo cual en algunas ocasiones llegamos a aplicar la analogía como el resultado de una interpretación. ${ }^{2}$

1 Giurista d'Impresa por la Università degli Studi di Bologna-Italia como becario por el Gobierno Italiano. Magister en Derecho Tributario y Fiscalidad Internacional por la Universidad de San Martin de Porres. Post grado en Arbitraje Internacional, Comercio Exterior y Medio Ambiente y Derechos Humanos en la American University - Washigton DC - Estados Unidos. Catedrático de los cursos de Derecho Empresarial, Títulos Valores y Derecho Corporativo en la Universidad Particular San Martín de Porres (USMP), Catedrático de los cursos de Derecho de Sociedades y Títulos Valores en la Universidad Femenina del Sagrado Corazón (UNIFE) y Catedrático de los cursos de Sociedades y Títulos Valores en la Universidad Privada del Norte (UPN). Director del Departamento Académico de la Facultad de Derecho de la Universidad Femenina del Sagrado Corazón. Presidente de la Asociación Peruana de Derecho Corporativo. Miembro de la Comisión Revisora de la Ley General de Sociedades.

2 MARIANA GASCÓN ABELLÁN. Teoría del razonamiento y la argumentación jurídica. Tema 2: Problemas interpretativos. P. 1 
La Dra.Gascón, considera que el punto de partida de la concepción intermedia es la toma de conciencia del carácter discrecional de la interpretación, y por consiguiente del componente ideológico o subjetivo que está presente en la misma, sobre todo cuando aparecen dudas o problemas interpretativos.

En algunos casos la interpretación puede ser es considerado como una actividad discrecional en nuestro ámbito lingüístico debido a que se le puede atribuir un significado, explicar o declarar el sentido de algo que queremos o necesitamos, principalmente de un texto.

"La discrecionalidad se manifiesta cuando la interpretación aparece como dudosa o problemática. Las principales dudas o problemas interpretativos que pueden presentarse se ligan a los tres contextos siguientes: (i) en el contexto lingüístico, cuando un determinado texto será interpretado según las reglas generales del lenguaje por el cual se esta comunicación, lo cual podría ser llamado lenguaje natural; (ii) en el contexto sistémico, cuando se pretender recurrir a un sistema esquematizado para poder entender el lenguaje o la comunicación misma a la que se quiere llegar, como por ejemplo en el ámbito legal que resulta ser amplio, de manera que su interpretación ha de hacerse teniendo en cuenta sus relaciones con el resto de los elementos del sistema; y (iii) contexto funcional, la ley tiene una relación con la sociedad ya que con la ley se pretende lograr algún efecto social, de manera que cuando se interpreta una determinada normativa ha de valorarse si cumple la función o los fines para los que ha sido creada." 3

Es por estas razones que la búsqueda de un significado jurídico contrastado en el campo del lenguaje puede resultar ser un poco peligroso para nuestros clientes como para nosotros mismos, ya que podríamos encontrarnos en problemas de ambigüedad, vaguedad, entre otros, que resultaría ser un problema sustancia en la aplicación de una determinada norma; es por dicha razón mi atención de estudio de la vaguedad sometida al razonamiento jurídico de la interpretación.

\section{EL PROBLEMA}

Nace una interrogante para poder definir el problema: ¿Las resoluciones judiciales están debidamente motivadas cuando contienen argumentación jurídica pertinente para la solución de la controversia? En las resoluciones judiciales de todos los órganos jurisdiccionales incluso en Supremos Tribunales, podemos encontrar deficiencias al momento de la elección de la norma, de la interpretación de la misma e incluso la no fijación por parte del magistrado de la norma. Sin embargo, existirá debida motivación cuando se cumple con el ordenamiento legal para la solución de una controversia, pensamos que no.

La debida motivación no sólo contempla el aspecto jurídico sino el aspecto lingüístico, en ese sentido la fundamentación de una resolución podría acarrear violación al principio de congruencia $^{4}$, como en muchos casos sucede, por cuanto los considerandos y el fallo no son congruentes y ello por problemas de carácter lingüístico: mala redacción, sabemos que un signo de puntuación puede cambiar el sentido de una oración o de un párrafo completo. La ambigüedad de las palabras es otro factor importante para determinar una real situación, la concordancia entre modos y tiempos y así podríamos citar " $n$ " factores que producirían cambios en la motivación de una resolución. Frente a este problema, sólo tocaremos el tema de la "vaguedad" que surge como desafió para la real y adecuada motivación jurídica. La vaguedad es un problema de los conceptos. ${ }^{5}$

Como señala el Doctor Jorge Portocarrero Quispe, la vaguedad se da en los conceptos por ejemplo: joven edad, anciano, etc, y en el Derecho tenemos varios términos vagos, señala por ejemplo plazo razonable, error sustancial, peligro inminente.

Estos términos son no cuantificables y por ello acarrean problemas para que el Juzgador pueda circunscribir una determinada conducta o situación dentro del concepto. 
La solución al problema de la vaguedad se da a través de la Teoría de los Campos Walter Jellinek, por el cual existen tres campos: Candidatos positivos "se refiere a los objetos que indubitablemente caen dentro del campo semántico de un concepto. Candidatos negativos: se refiere a los objetos que indubitablemente no caen dentro del campo semántico de un concepto y candidatos neutros: se refiere a los objetos que no son clasificables de manera indubitable, es decir sobre los que existen dudas sobre si caen dentro del campo semántico de un concepto.

En caso de duda, se debe optar por el candidato neutral. La vaguedad (los candidatos neutrales) no se soluciona apelando al contexto, sino a través de una determinación del intérprete. En el caso del derecho, a través de una decisión autoritativa por parte del intérprete legitimado, basada en una argumentación suficiente.

Si bien, la teoría de los campos pareciera dar solución al problema de la vaguedad, no es utilizada por los magistrados al momento de resolver y lo que pretendemos es que se elimine los términos de vaguedad al menos en el campo del Derecho, utilizando términos precisos, intentaremos dar una posible visión del problema y posible solución al mismo.

\section{PROBLEMAS DE CONTEX- TO LINGÜISTICO EN EL RAZONAMIENTO JURÍDICO}

Los problemas interpretativos surgen cuando el lenguaje ju- rídico o en si la misma norma promulgada plantea dudas en su aplicación; tal es así, que en algunas ocasiones surgen problemas del contexto lingüístico. Entre estos problemas podemos encontrar a la (i) ambigüedad; (ii) imprecisión o vaguedad.

\section{a. PROBLEMAS DE AMBI- GÜEDAD}

Como es bien sabido por nosotros, la ambigüedad tal como lo señala el Diccionario de la Real Academia Española, se presenta cuando un determinado contexto puede entenderse de varias maneras, modos, admitiendo distintas interpretaciones que podrían originar ciertas confusiones en una determinada conversación o pretensión determinada.

Esto quiere decir que el problema no radica en la palabra misma, sino en el significado en la que se expresan de acuerdo a la ocasión y contexto en el que se usen; los claros ejemplos y que latentemente vemos en el mundo del derecho es que una palabra en el sentido común de las personas puede significar una cosa determinada y en el mundo del derecho significa otra. Por ejemplo, la palabra "auto", al respecto, podemos diferir de dicha palabra, los siguientes significados:

Para la sociedad: Que se mueve por sí mismo. Se dice principalmente de los vehículos que pueden ser guiados para marchar por una vía ordinaria sin necesidad de carriles y llevan un motor, generalmente de explosión, que los pone en movimiento.

Para el Derecho: Forma de resolución judicial, fundada, que decide cuestiones secundarias, previas, incidentales o de ejecución, para las que no se requiere sentencia.

Por otro lado, y acoplando un ejemplo más legal el Dr. J. Igartua mencionando lo siguiente en cuanto a la "Ambigüedad semántica”. Por ejemplo, el artículo 163 del Código penal argentino agravaba el hurto cuando fuera de "ganado". Algunos entendían por "ganado" un nombre colectivo (como "rebaño"), de manera que quien se apoderase de una sola vaca no incurría en el supuesto; otros, por el contrario, admitían que un único animal de ciertas especies se considera "ganado"

Sin embargo, esta situación podría generar un conflicto únicamente en el inicio de una conversación o en el planteamiento de una pretensión, sujeto a poder acoplarse en el momento de la expresión de las personas, o en el contexto en el cual se maneje; esto quiere decir que aquí no habría mayor razonamiento jurídico que un simple buen planteamiento del problema, a diferencia de la vaguedad, que a continuación desarrollaremos y es materia de la presente investigación.

\section{b.PROBLEMAS DE VAGUE- DAD O IMPRECISIÓN}

En resumen podemos decir que la ambigüedad surge cuando la palabra tiene varias interpretaciones para definir o establecer un determinado contexto, a diferencia de la vaguedad que se caracteriza por la variedad de conceptos que 
puede tener una palabra. Este último concepto se puede asemejar mucho con la palabra "vago", ya que el problema de la palabra va a centrarse en su significado.

Según la Dra. Gascón, todas las expresiones lingüísticas, al menos las del lenguaje natural, presentan algún grado de indeterminación, que en el lenguaje común de las personas se pueden adaptar al momento; sin embargo, en el área legal puede ser muy peligroso confundir conceptos cuando pretendemos defender un caso o establecer un punto determinado, ya que el lenguaje lo debemos de subsumir en una ley determinada, que como se ha desarrollado anteriormente, en algunas ocasiones podría no ser el lenguaje lo que este mal, sino la falta de regulación que tiene una norma, lo cual llevaría a una mala praxis normativa a un caso concreto.

Es evidente que la vaguedad alcanza un mayor grado de aplicación cuando el legislador usa conceptos que integran una gran carga valorativa de significados; es decir, cuando usa fundamentos que para nuestra legislación resultan ser típicamente vagos, como por ejemplo daño grave, administración incorrecta, conducta reprobable, convivencia intolerable, notoria importancia, entre otros, que lastimosamente una persona que no haya estudiado leyes no los entiende. Para tal caso Mariana Gascón, cita como ejemplo que la "perturbación de las facultades mentales" suele ser considerada como una atenuante en muchos ordenamientos; pero, antes de poder analizar este pequeño fragmento de la normativa, nos haríamos la siguiente pregunta ¿dónde empieza esa perturbación?

Sin embargo, estos problemas que nos pueden ser muy difíciles de interpretar, no solo son vistos a nivel nacional, por ejemplo en España en el "artículo 369.3 del Código penal español regula una agravación de la pena en los delitos de tráfico de drogas cuando la cantidad de droga objeto del delito sea 'de notoria importancia', con lo cual nuevamente nos hacemos la pregunta, ¿qué cantidad de droga es de notoria importancia?

Y lo mismo sucede cuando el artículo 1,255 del Código $\mathrm{Ci}$ vil Español al tipificar que los contratantes no puede establecer pactos 'contrarios a la moral'; o cuando el artículo 1,555 del mismo cuerpo legal establece que el arrendatario deberá usar la cosa arrendada 'como un diligente padre de familia’.

No cabe duda que en la determinación de si alguien tiene perturbadas sus facultades mentales, o si una cantidad de droga es de notoria importancia, o si un pacto es contrario a la moral, o una conducta se aparta del modelo del buen padre de familia queda un amplio campo a la discrecionalidad del intérprete" , con lo cual podríamos entrar hasta en una falacia y no a lo que realmente el legislador quiso proponer al promulgar una norma determinada.

Estos problemas lingüísticos que surgen en el razonamiento jurídico pueden perjudicar, no solo al lenguaje común o en general a una asesoría jurídica, sino también en el fallo que emite un Juez, en el amparo de una obligación que todo magistrado debe asumir a raíz del principio de congruencia procesal, esto quiere decir que el Juez debe dictar sus resoluciones con el sentido y alcances de las peticiones formuladas por las partes en el amparo de la ley.

Sin embargo, la vaguedad del lenguaje podría resultar peligroso si una determinada palabra en el petitorio podría no resultar clara, con lo cual el juez que resuelve un caso podría emitir una sentencia (i) ultra petita, si en caso el petitorio tenga un determinado sentido, pero el juez resuelva de distinta manera; (ii) extra petita, si el juez al no interpretar una determinada palabra otorga más de lo que se está solicitando; y (iii) infra petita, cuando el juez otorgue o resuelva menos de lo que se ha solicitado.

Entre estos ejemplos podemos advertir un caso que su pretensión radica en suprimir el segundo nombre de una partida, sin embargo, esto podría traer dos consecuencias: (i) que a la interpretación de un juez pueda resultar ser la modificación total del nombre y (ii) en otro supuesto podemos advertir una variación no sustancial del nombre. Con lo cual al ver esta vaguedad podemos advertir que si un juez declara admisibilidad o la improcedencia de esta pretensión, puede resultar contraproducente a la misma pretensión a la que se quiere llegar o en sumas cuentas puede ser un resguardo 
para que casos similares sean tramitados en un juez competente.

Es por este lado que queremos hacer el estudio jurídico de la vaguedad tal como a continuación lo desarrollaremos.

\section{LA APLICACIÓN DE LA VA- GUEDAD EN EL SISTEMA JURÍDICO}

Dirigir los conflictos sociales de una forma vaga deja inseguridad a las personas que deben acatar las normas y de la misma forma a aquellos que aplican las normas. Por lo tanto, no parece repulsivo pensar que la vaguedad podría considerarse anti ética con respecto a un Estado de Derecho. Sin embargo, algunos autores no considera que ello sea del todo cierto, al respecto el Dr. Endicott señala que:

"Todo sistema legal necesita reglas vagas. La normativa general de la inmensa variedad de actividades que deben normarse en cualquier comunidad es imposible sin leyes vagas. Ninguna comunidad podría lograr el control ordenado y regular sobre la vida comunitaria, que es característica de los sistemas legales, sin leyes vagas."

Para el autor, en resumidas cuentas, no es necesario eliminar la vaguedad de la interpretación de la ley para que un país logre alcanzar un Estado de Derecho. Por el contrario, la gobernabilidad por ley necesita normas vagas. Si existe una buena razón para la vaguedad de las leyes y si el sistema tiene tribunales independientes para resolver las disputas que inevitablemente resultan de la aplicación de normas vagas, puede hacer todo lo que esperamos de un sistema legal.

Sin embargo, no rescato lo que el autor nos ha señalado, ya que la vaguedad puede resultar ser un elemento importante para la eliminación de un Estado de Derecho si aquella persona que asuma el control del estado no lo sabe llevar adecuadamente, eso quiere decir que estaríamos a dispensas de que nos toque un buen legislador para la promulgación y aplicación de la norma.

Con lo cual cuando, en mi opinión, las leyes que no son claras podrían llevar a decisiones judiciales que pueden ser arbitrarias, por lo tanto en un sistema legal se perdería la naturaleza de Estado de Derecho. $Y$ ello nos deja pensando en lo siguiente ¿En qué situaciones la vaguedad desmerece o no el Estado de Derecho?

Lastimosamente, las normas más vagas de los sistemas legales se encuentran en las constituciones de los países, con lo cual no solo puede perjudicar a otra norma especial, sino también al manejo de un país entero, teniendo en cuenta que podría afectar derechos humanos.

Para nadie es desconocido que para elaborar una nueva ley se tomen como modelo otros ordenamientos, incluso de sistemas jurídicos diferentes al nuestro, como lo hicieron los primeros legisladores que redactaron nuestra Constitución. Ellos tomaron elementos de diversas Constituciones como por ejemplo las de Fran- cia y de Estados Unidos, pero incluyeron algunos de manera equivocada, que por una mala traducción los legisladores incorporan en nuestros artículos normas que no se adecuan a la realidad de nuestro país, o que dejan a un concepto muy vago del mismo, obteniendo una interpretación deficiente de la norma, apareciendo en nuestra historia la vaguedad en el razonamiento jurídico aplicado a la realidad empírica.

En contrario sensu el Dr. Redondo, hace mención respecto de la vaguedad de las normas al señalar que:

"La completitud del Derecho viene a proclamar que el sistema jurídico es capaz de contener una solución para cualquier controversia jurídica que planteen los ciudadanos. De modo que cualquier caso ha sido previsto y está regulado por el Ordenamiento, y en todos sus aspectos. $Y$ así, una acción o situación está "regulada" y, en consecuencia, está "determinada" en un sistema jurídico, "si a dicho sistema pertenece una norma que califique esa acción". De este modo, del conjunto de las normas jurídicas se predica completitud y determinación cuando para toda situación y acción, actual o posible (futura), aquéllas disponen siempre de una calificación jurídica para cualquier caso dado que se presente."

Siguiendo nuestra lógica, el Dr. HART, H.LA., hace un planteamiento al señalar que:

“(...) no concibe a la vaguedad en la legislación como un rasgo negativo, esto es, como un defecto de la ley, pero tampoco 
la entiende como una característica especialmente óptima del Derecho. Sino que, ante las concepciones negativas y positivas de las teorías jurídicas acerca de la presencia de la vaguedad en el Derecho, la posición hartiana es más bien de constatación e imparcialidad."

\section{LA NECESARIA VAGUEDAD EN LA LEGISLACIÓN}

Otras de las teorías jurídicas que tienen una visión diferente a la concepción tradicional en relación a la imprecisión de la legislación es la posición que ha mantenido recientemente el autor T. ENDICOTT. No sólo constata la existencia irremediable de vaguedad en la legislación en virtud de la estructura abierta que presenta la ley, sino que incluso lo considera una característica positiva del Derecho y necesaria para la misma.

La concepción que tiene ENDICOTT respecto de la presencia de vaguedad en el Derecho es la de refutar de una forma más radical la visión hartiana, la precisión y determinación de la legislación como ideal característico del Derecho. La forma que se le quiere dar a esta teoría es una perspectiva de una tesis lingüística sobre el Derecho y por otro lado sobre la indeterminación jurídica, sustentada en la vaguedad del lenguaje en el derecho.

Así, en primer lugar, el concepto de vaguedad del lenguaje legislativo conlleva en sí una tesis lingüística en la argumentación del Profesor de Oxford. A este respecto, él atribuye dos características a las pala- bras que son vagas. La primera característica hace referencia a las "dudas" y el "desacuerdo" que surgen cuando se aplican dichas palabras vagas. En relación a la legislación, este rasgo es típico de la existencia de reglas indeterminadas en el Derecho.

Tal como lo menciona J. Alberto del Real Alcalá el "principio de tolerancia, nos viene a decir que las palabras vagas, precisamente porque al ser vagas ni tienen ni pueden tener límites definidos en su aplicación, parecen tolerar como aplicaciones similares diferencias que son insignificantes (pero que son diferencias), y que si se repiten de forma acumulativa llevan a grandes paradojas. Por ejemplo, en el ámbito del Derecho, estas diferencias que podrían parecer insignificantes pueden generar la distinción entre declarar culpable o inocente a distintas personas en casos idénticos 0 parecidos pudiéndose apreciar claramente que a la hora de juzgar casos similares esas decisiones afectan la discrecionalidad del derecho.

\section{LA VAGUEDAD EN LAS RESO- LUCIONES JUDICIALES}

$\mathrm{Si}$, partimos que el Juzgador debe basarse en la norma para poder resolver y debe realizar un criterio de conciencia para establecer la cuantificación de los términos de vaguedad en el Derecho, entonces el problema va más allá de la solución de la teoría de los campos, propuesta por Walter Jellinek, por cuanto el problema no nace por la deficiente interpretación o mala interpretación por parte del Juzgador, sino nace de la propia normatividad, es decir la vaguedad se origina en la propia norma.

Usemos el término de plazo razonable, recogido por la legislación nacional en materia penal por ejemplo de instrumentos supranacionales, en este caso por:

El plazo razonable en términos de la Convención Americana sobre Derechos Humanos, está referido a que "Toda persona tiene derecho a ser oída, con las debidas garantías y dentro de un plazo razonable, por un juez o tribunal competente, independiente e imparcial, establecido con anterioridad por la ley, en la sustanciación de cualquier acusación penal formulada contra ella, o para la determinación de sus derechos y obligaciones de orden civil, laboral, fiscal o de cualquier otro carácter." .

Al no existir una definición clara de plazo razonable o los parámetros del mismo, el Juez podrá utilizar todas las herramientas necesarias para establecer cuál considera como plazo razonable, pero esa interpretación subjetiva puede ser revertida por otros argumentos no expuestos por el Juzgador no por deficiencia sino por óptica al momento de resolver. Ello, conlleva a que si bien es cierto en el ejemplo citado no podría señalarse un plazo fijo o determinado, por cuanto ya no se tratará de plazo razonable, la intención al crear este término, es garantizar el debido proceso por las circunstancias que se pudieran originar. Por consiguiente, no tratamos de establecer que no existan términos de vaguedad en las re- 
soluciones judiciales, sino que al existir conceptos jurídicos que contienen vaguedad, ella se podría minimizar a través de fijación de parámetros cualitativos o condiciones.

Así por ejemplo, en el plazo razonable no fijaremos rango de tiempo sino circunstancias como término de la distancia, relación para la obtención de la prueba, criterios de colaboración, etc. Ello debería estar establecido en la norma, para evitar que el Juzgador utilice otros criterios, claro está podría pero sin apartarse de los principales ya señalados por la norma y con ello se evitaría, la interpretación errónea por parte de otros actores dentro del proceso.

\section{CONCLUSIONES}

PRIMERA: La vaguedad es un problema lingüístico que produce una motivación deficiente en las resoluciones judiciales, por cuanto no basta la aplicación correcta de los dispositivos legales sino también el uso adecuado del lenguaje.

SEGUNDA: La vaguedad no se da sólo en el lenguaje sino en los conceptos jurídicos y por ello el Juzgador puede dar una interpretación errónea al momento de fundamentar su resolución, al tratarse de un concepto no cuantificable.

TERCERA: La vaguedad no es un problema lingüístico en el campo del derecho propio del idioma sino de la incompleta técnica legislativa al momento de emitir una norma.

CUARTA: Para minimizar el problema de la vaguedad es necesario señalar las condiciones o los parámetros al momento de la creación de la norma, señalando los aspectos cualitativos principales para que el Juzgador pueda resolver. 